\title{
Methods to Evaluate the Aging Grades of Reclaimed Asphalt Binder
}

\author{
Changjiang Kou ${ }^{1,2}$ (D), Peng Xiao ${ }^{1, *}$, Aihong Kang ${ }^{1}$, Peter Mikhailenko ${ }^{2}$, Hassan Baaj ${ }^{2}$ \\ and Zhengguang $\mathrm{Wu}^{1}$ \\ 1 Department of Civil Science and Engineering, Yangzhou University, Yangzhou 225127, China; \\ changjiang.kou@uwaterloo.ca (C.K.); kahyzu_mail@163.com (A.K.); zgwu@yzu.edu.cn (Z.W.) \\ 2 Department of Civil and Environmental Engineering, University of Waterloo, Waterloo N2L 3G1, ON, Canada; \\ p2mikhai@uwaterloo.ca (P.M.); hassan.baaj@uwaterloo.ca (H.B.) \\ * Correspondence: xpyzu_mail@163.com; Tel.: +86-139-052-77934
}

Received: 18 October 2017; Accepted: 20 November 2017; Published: 23 November 2017

Featured Application: The development of aging grades for reclaimed asphalt binder can be used to guide the design of RAP mixtures.

\begin{abstract}
The use of reclaimed asphalt pavement (RAP) is of great significance for alleviating the problem of resource waste and land space occupation in the context of asphalt pavement. However, the use rate of RAP is still low in many countries because of limited understanding and no unified recycling guidelines, especially in terms of materials classification and aging grades. In this study, reclaimed asphalt pavements from sixteen different sections in southern China were collected, including with base and polymer modified asphalt (PMA). The performance of the reclaimed asphalt binder $(\mathrm{RAB})$ at low, average and high temperatures was tested, using various methods, to find suitable indexes for categorizing aging grades. The viscosity $\left(135^{\circ} \mathrm{C}\right)$ and penetration $\left(25^{\circ} \mathrm{C}\right)$ were found to distinguish the aging degree of RAB the most consistently, and served as the indices to classify the RAB into different grades. To simplify the evaluation of aging grades, a comprehensive service life was determined using the Analytic Hierarchy Process, taking service years and surface levels into account. As a result, a good correlation was found between comprehensive service life and the aging grades.
\end{abstract}

Keywords: reclaimed asphalt pavement (RAP); reclaimed asphalt binder (RAB); aging grade; comprehensive service life

\section{Introduction}

The use of reclaimed asphalt pavement has contributed to saving a great amount of asphalt and aggregates and alleviating the problem of resource waste [1], land occupation and secondary pollution, which allowed this technology to achieve rapid development in last two decades [2]. As early as the end of last century, reclaimed asphalt pavement (RAP) was utilized for weaker pavement layers such as the base or sub base [3]. Generally, RAP contents from $10 \%$ to $30 \%$ by mass of the mixture are considered to be adequate to produce asphalt mixtures with performance similar to conventional mixtures [4-6]. Rejuvenators, additives and warm mix asphalt technology are usually employed to improve the effective contribution of RAP binder towards the total binder of the mixture [7-9]. However, the use of RAP is at a very low level in many developing countries, for there are no relevant and unified recycling guidelines. Since the key to recycling old asphalt pavement is the rejuvenation and remobilization of asphalt binder [10,11], it would be of great significance to establish a RAP evaluation guideline based on the condition of the reclaimed asphalt binder (RAB). 
The classification of RAP materials is the basis of its efficient utilization. Today however, arbitrary stockpiling of RAP is still a common practice from the lack of standards or specifications [12,13], especially in Asia and Africa. Different pavement layers are paved with different asphalt binders, such as conventional base asphalt, lake or rock asphalt, polymer modified asphalt (PMA), fiber asphalt and so on [14]. Recycling of unclassified RAP may lead to many difficulties, depending on the aging characteristics of different RAP binders. The types of binders, pavement layers, service life and position of lanes should be taken into account in milling and recycling.

The aging of asphalt binder is a long-term oxidation process. According to SARA (saturate, aromatic, resin and asphaltene) analysis for binder aging $[15,16]$, oxidative polymerization reaction causes mutual transformation of different components. The lighter aromatics in the binder are transformed into colloids while the polar aromatics into asphaltenes. This chemical process finally leads to a stiffer asphalt binder $[17,18]$. Most researchers have used accelerated laboratory aging to study the composition and property changes of asphalt binder during aging process. Ji et al. proposed critical aging viscosity as the aging grade index. They divided aging grades according to the relationship between the viscosity of the aged binder and the critical aging viscosity [19]. Kuang divided aging asphalt into three grades by penetration, namely, mild aging, moderate aging and severe aging [20]. It was also found that the penetration of asphalt with severe aging could be restored by adding a rejuvenator and modified asphalt, moderately aged asphalt by adding just a rejuvenator and mildly aged asphalt by only adding some virgin asphalt. F. Mazzotta et al. put forward that the short-term aging simulation should conducted at the equiviscous temperature instead of the standard temperature of $163^{\circ} \mathrm{C}$ to overcome the non-homogeneous distribution of the binder on the glass [21].

A number of studies have been conducted to evaluate the aging degree of recycled virgin asphalt and modified asphalt, including SARA analysis, softening point, penetration, ductility, Brookfield viscosity and so on. However, this work has not been put towards developing of quantitative aging grades of RAP binder. Most studies have simulated aging virgin asphalt binder, but not field sourced reclaimed asphalt binder (RAB). In China, as in most other places, there are no uniform standards for using RAP. PMA has been widely used in asphalt pavement [22-24], but scholars mainly focused on the study of aging base asphalt RAP. The purpose of this study is to develop a guide for RAP binder aging and grading evaluation for base and polymer-modified asphalt, based on performance tests and analysis of real reclaimed asphalt pavement materials from sixteen different field sections.

Some studies have attempted to find a comprehensive evaluation method by using investigated data and engineering experience, which could also to some extent decrease laboratory work. In this context, the analytic hierarchy process (AHP) was initially developed, making the most use of field data, laboratory results and experts' experience, for applications in multicriteria decision making, planning and resource allocation and in conflict resolution [25,26]. In the present time, the AHP has been widely used in the fields of social studies, education, manufacturing and civil engineering due to the process simplifying complex decisions into a series of one-on-one comparisons [27]. It was applied to infrastructure management earlier by S. L. Tighe for comparing seven maintenance, rehabilitation, and reconstruction strategies for asphalt pavements [28]. Guo, Zhang developed a comprehensive evaluation system on the basis of the AHP, by which ratings for asphalt pavement construction quality were generated. The advantage of this system is that it allows experts to assign relative importance between any related pairs of indices $[29,30]$. Other publications also focused on the application of AHP in determining the reliability index of asphalt pavement construction, the comprehensive performance grades of warm mix asphalt (WMA), and the damage condition of asphalt pavement [31-33]. As for the reclaimed asphalt binders, a comprehensive index incorporating the key influencing factors of aging and engineering experience would help divide the RABs into different grades, and help save on laboratory testing work. 


\section{Materials and Methods}

\subsection{Reclaimed Asphalt Pavement}

Based on the investigations made in southern China, sixteen RAP samples with different service years, surface depths levels and different degrees of damage were chosen for evaluating RAB aging grades. Images of some are shown in Figure 1.
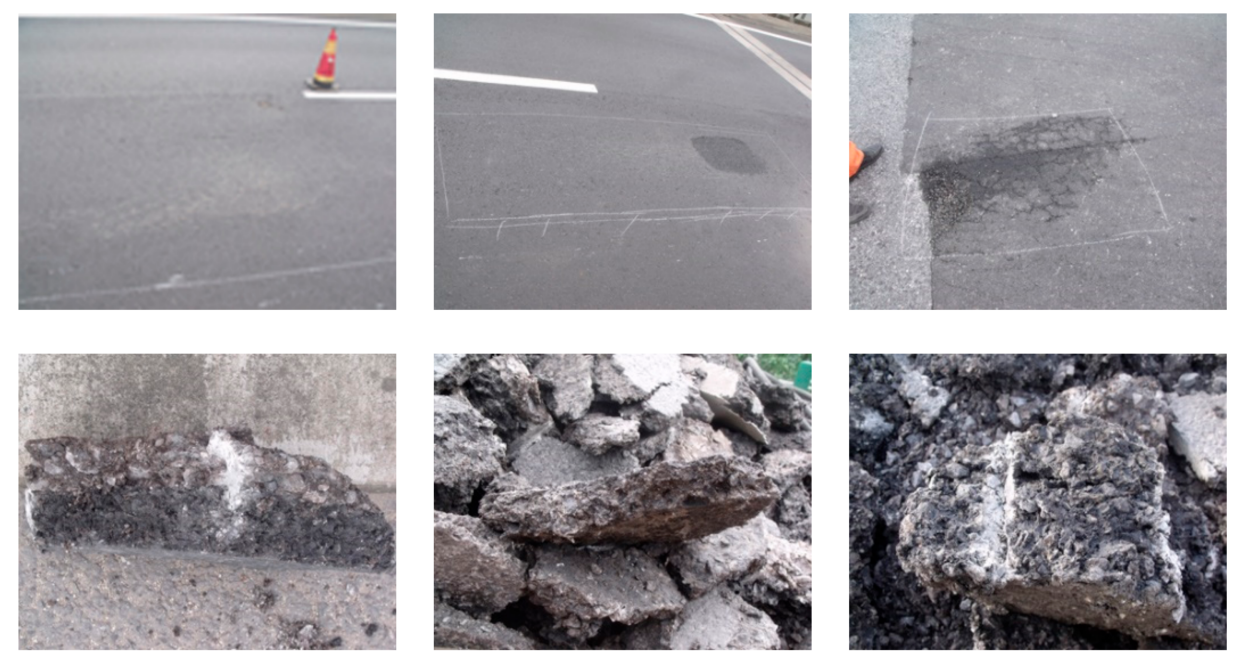

Figure 1. Pictures of representative reclaimed asphalt pavement (RAP) samples.

The original design, repair and maintenance documents were available, and examined for each RAP source, noting the binder type, service years and milling depth for the upper, middle and lower surface courses. The typical asphalt pavement structure is shown in Figure 2, with the surface layers indicated approximately. Detailed information is presented in Table 1.

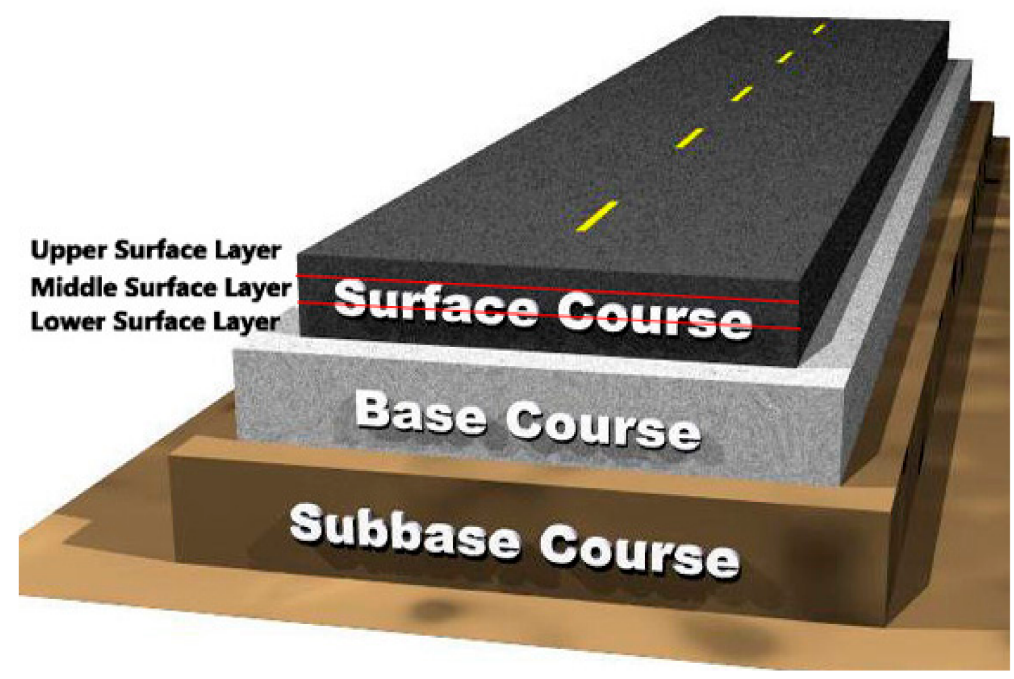

Figure 2. Typical asphalt pavement structure. 
Table 1. Service life and origin of reclaimed asphalt pavements (RAPs).

\begin{tabular}{|c|c|c|c|c|c|c|c|c|c|c|}
\hline \multirow{3}{*}{ Binder Type } & \multirow{3}{*}{ No. } & \multicolumn{9}{|c|}{ Surface Layer } \\
\hline & & \multicolumn{3}{|c|}{ Upper Surface Course } & \multicolumn{3}{|c|}{ Middle Surface Course } & \multicolumn{3}{|c|}{ Lower Surface Course } \\
\hline & & $\begin{array}{l}\text { Binder } \\
\text { Type }\end{array}$ & $\begin{array}{c}\text { Service } \\
\text { Years (y) }\end{array}$ & $\begin{array}{l}\text { Milling } \\
\text { Depth } \\
\text { (cm) }\end{array}$ & $\begin{array}{l}\text { Binder } \\
\text { Type }\end{array}$ & $\begin{array}{c}\text { Service } \\
\text { Years (y) }\end{array}$ & $\begin{array}{l}\text { Milling } \\
\text { Depth } \\
\text { (cm) }\end{array}$ & $\begin{array}{l}\text { Binder } \\
\text { Type }\end{array}$ & $\begin{array}{l}\text { Service } \\
\text { Years (y) }\end{array}$ & $\begin{array}{l}\text { Milling } \\
\text { Depth } \\
\text { (cm) }\end{array}$ \\
\hline & 01 & - & - & - & SBS & 3 & 6 & Base & 3 & 4 \\
\hline & 02 & SBS & 2 & 4 & SBS & 3 & 6 & Base & 3 & 3 \\
\hline & 03 & SBS & 2 & 4 & SBS & 3 & 3 & - & - & - \\
\hline SBS $^{1}$ & 04 & SBS & 3 & 4 & SBS & 3 & 3 & - & - & - \\
\hline Modified & 05 & SBS & 2 & 4 & SBS & 6 & 3 & - & - & - \\
\hline Asphalt & 06 & - & - & - & SBS & 6 & 6 & Base & 12 & 7 \\
\hline \multirow[t]{6}{*}{ Binder (SBS) } & 07 & SBS & 2 & 4 & SBS & 8 & 5 & - & - & - \\
\hline & 08 & - & - & - & SBS & 8 & 6 & Base & 8 & 4 \\
\hline & 09 & - & - & - & SBS & 12 & 6 & Base & 12 & 7 \\
\hline & 10 & - & - & - & SBS & 12 & 5 & - & - & - \\
\hline & 11 & - & - & - & - & - & - & Base & 3 & 4 \\
\hline & 12 & Base & 3 & 4 & - & - & - & - & - & - \\
\hline Base Asphalt & 13 & Base & 4 & 5 & - & - & - & - & - & - \\
\hline \multirow{3}{*}{ Binder (Base) } & 14 & Base & 7 & 3 & - & - & - & - & - & - \\
\hline & 15 & Base & 9 & 4 & - & - & - & - & - & - \\
\hline & 16 & Base & 10 & 5 & - & - & - & - & - & - \\
\hline
\end{tabular}

Taking sample 4 as an example, the schematic diagram of repair and maintenance history shows information about the RAP sources obtained from the original design, repair and maintenance documents as shown in Figure 3. Sample 4 was recycled in September 2012 from the upper surface layer and middle surface layer paved in May 2009. Therefore, its service life would be three years. The information for the other 15 samples were determined in the same way.

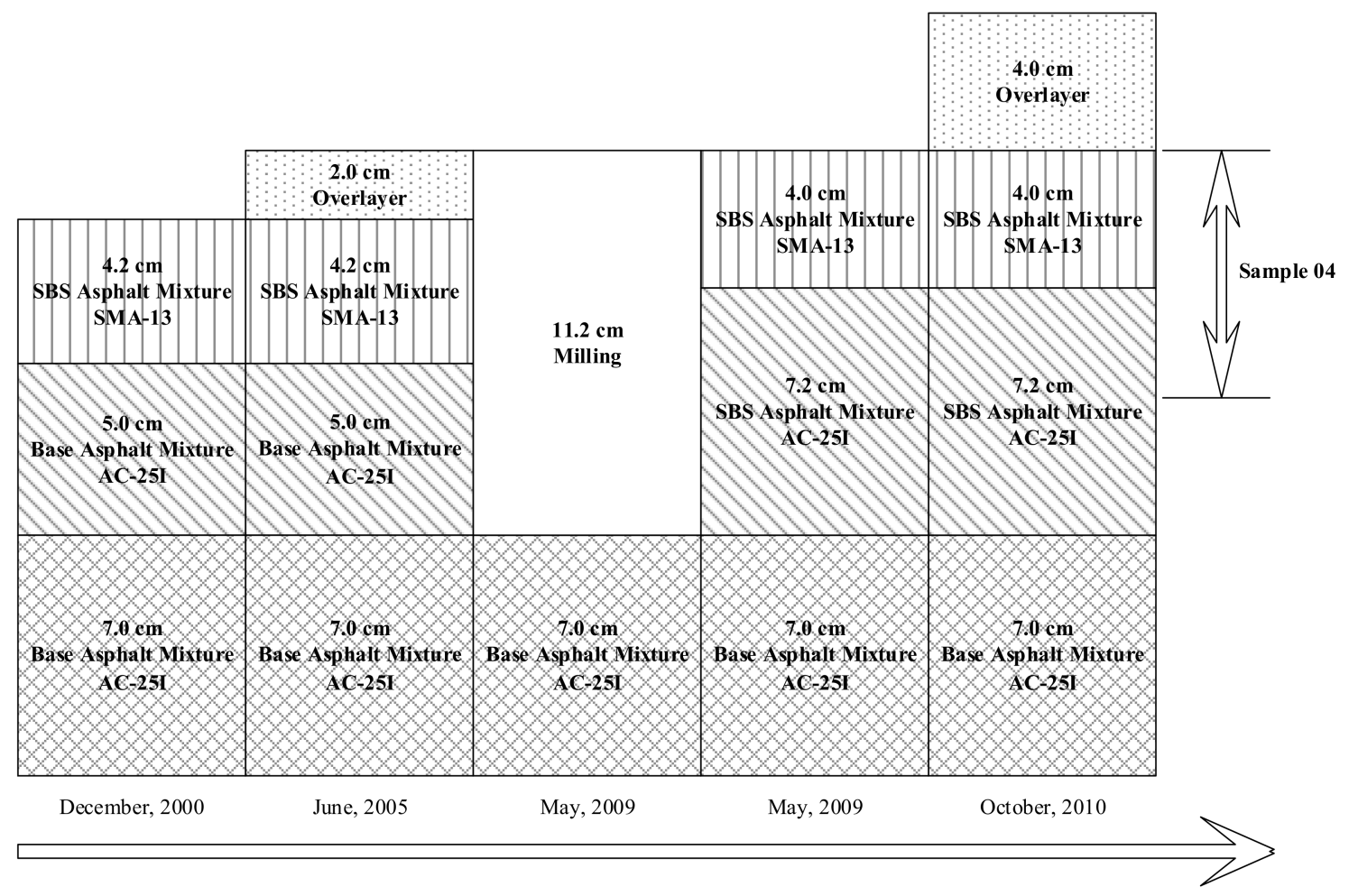

Figure 3. Schematic diagram of repair and maintenance history of pavement surface course. 
The road sections were carefully selected so that they had the same base and SBS (styrene-butadiene-styrene block copolymers) modified original asphalt. The original physical properties of the asphalt binders were attained from design documents, and are shown in Table 2.

Table 2. Physical properties of original asphalt binders.

\begin{tabular}{|c|c|c|c|c|c|c|}
\hline $\begin{array}{l}\text { Properties }{ }^{1} \\
\text { Binder Type }\end{array}$ & $\begin{array}{l}\text { Point of } \\
\text { Softening } \\
\left({ }^{\circ} \mathrm{C}\right)\end{array}$ & $\begin{array}{c}135^{\circ} \mathrm{C} \\
\text { Viscosity } \\
(\mathrm{Pa} \cdot \mathrm{s})\end{array}$ & $\begin{array}{c}25{ }^{\circ} \mathrm{C} \\
\text { Penetration } \\
(0.1 \mathrm{~mm})\end{array}$ & Ductility (cm) & $\begin{array}{l}\text { Fatigue Design } \\
\text { Temperature }\left({ }^{\circ} \mathrm{C}\right)\end{array}$ & $\begin{array}{c}-12{ }^{\circ} \mathrm{C} \text { Creep } \\
\text { Stiffness (MPa) }\end{array}$ \\
\hline Base Asphalt & 46 & 0.58 & 60 & $100\left(15^{\circ} \mathrm{C}\right)$ & 15 & 110 \\
\hline SBS Modified Asphalt & 60 & 1.6 & 52 & $32\left(5^{\circ} \mathrm{C}\right)$ & 12 & 98 \\
\hline
\end{tabular}

${ }^{1}$ All properties were tested as per test specification of asphalt and asphalt mixtures for highway of China.

\subsection{Reclaimed Asphalt Binder}

Centrifugal extraction was selected as the extraction method, which is a cold process, and minimizes any further aging [34]. The solvent used was trichloroethylene, a commonly used chlorinated solvent [35] Abson recovery was used to recover the binders after extraction [36,37]. The extraction and recovery process is shown in Figures 4 and 5.

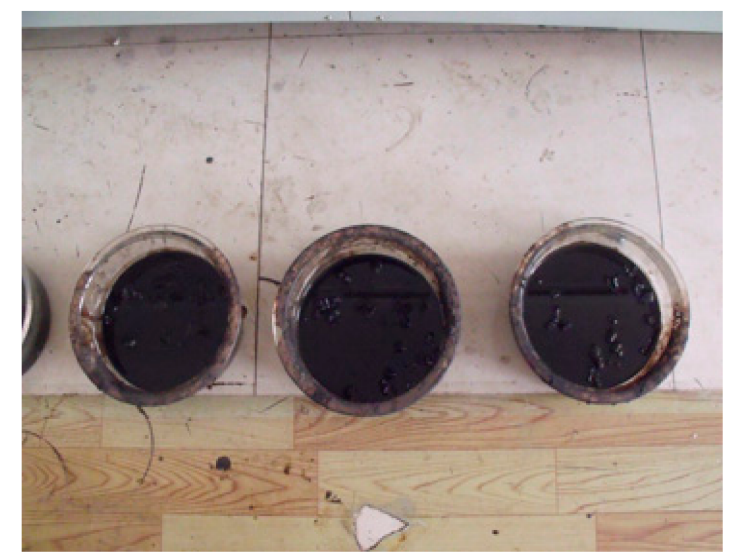

(a)

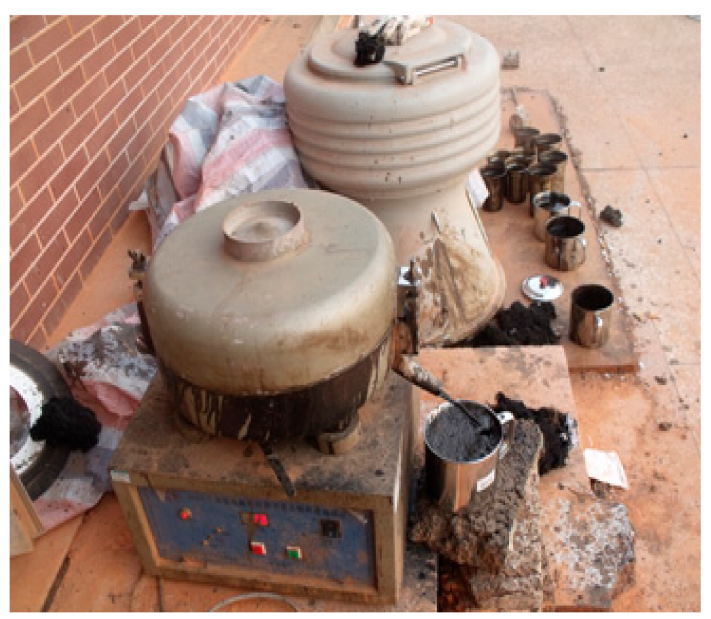

(b)

Figure 4. Cont. 


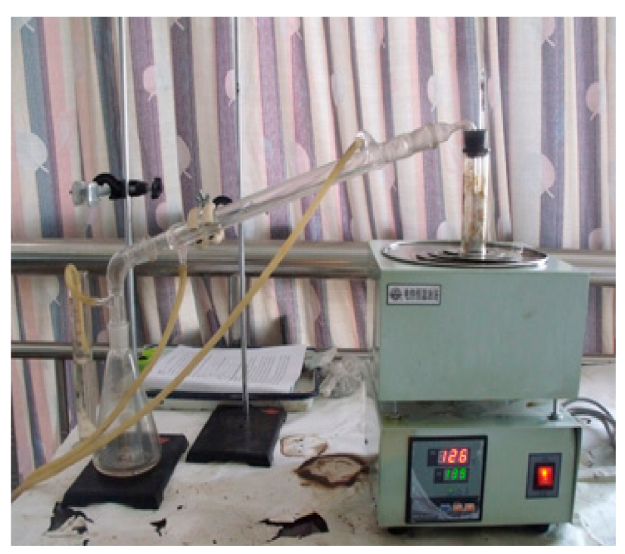

(c)

Figure 4. Extraction and recovery of reclaimed asphalt binder (RAB). (a) Sample soaking; (b) Centrifugal extractor and separator; (c) Abson recovery.

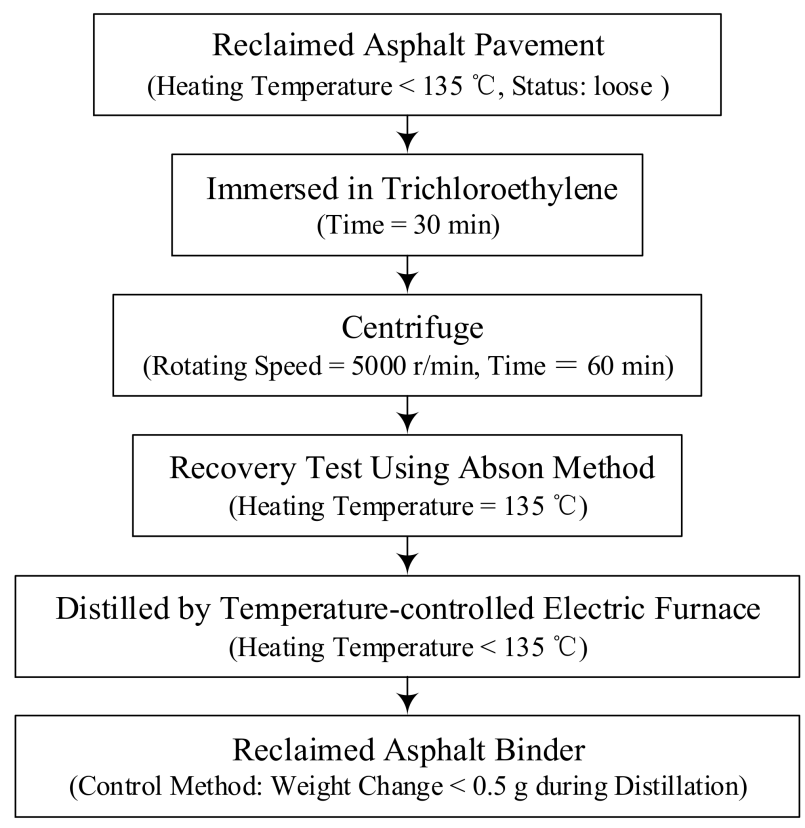

Figure 5. Flowchart of the procedure of extraction and recovery.

\subsection{Performance Testing}

\subsubsection{Basic Performance Indexes}

Softening point (ring and ball), penetration at $25{ }^{\circ} \mathrm{C}$ and ductility at $5{ }^{\circ} \mathrm{C}$ were conducted to test the performances of each RAB [38].

\subsubsection{Rotational Viscosity}

Asphalt binders must have sufficient fluidity at high temperatures so that they can meet the requirements of plant mixing and compaction. A rotational viscometer was used to measure the viscosity and evaluate its workability during mixing and compaction [39]. 


\subsubsection{Dynamic Shear Rheology}

The rheology of the samples was tested by the Dynamic Shear Rheometer (DSR) [40]. The DSR applies a shear stress to an asphalt film between two parallel metal plates. The lower plate is fixed, while the upper one oscillates in the form of sinusoidal curve at a frequency of $10 \mathrm{rad} / \mathrm{s}$. The complex shearing modulus $\left(G^{*}\right)$ and phase angle $(\delta)$ are used to represent the rheological performance and used to calculate the recoverable deformation (elastic part) and the permanent deformation (viscous part) of asphalt binders. In this study, a temperature scanning (from high temperature to low temperature) test was conducted on sixteen RABs. The fatigue factor $\left(G^{*} \cdot \sin \delta\right)$ will increase with the decrease in test temperature. The critical temperature below which the fatigue factor is more than the required value $(5000 \mathrm{kPa})$ is the fatigue design temperature. A lower fatigue design temperature represents the stronger fatigue cracking resistance.

\subsubsection{Bending Beam Rheology}

Finally, the samples were tested by Bending Beam Rheology (BBR). BBR provides a measure of the low temperature stiffness and relaxation properties of asphalt binders [41]. These parameters give an indication of the ability of asphalt binder to resist low temperature cracking. As with other Superpave binder tests, the actual temperatures anticipated in the area where the asphalt binder will be placed determined the test temperatures used. It uses a small asphalt binder beam $(125 \mathrm{~mm}$ long, $12.5 \mathrm{~mm}$ wide and $6.25 \mathrm{~mm}$ thick) immersed in a cold liquid bath, and a load is applied to the center of the beam. Then, the deflection is measured versus the time. Creep stiffness and creep rate of the binders were determined at a loading time of $60 \mathrm{~s}$.

\section{Results}

The performance data of the RABs are shown in Figures 6-11, comparing them with the properties of the respective original binders.

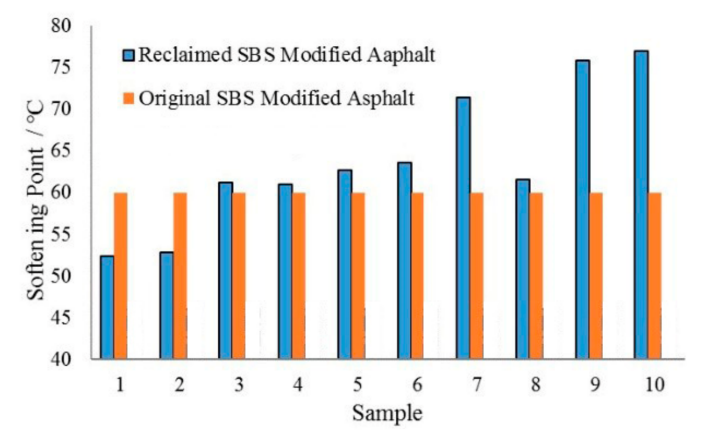

(a)

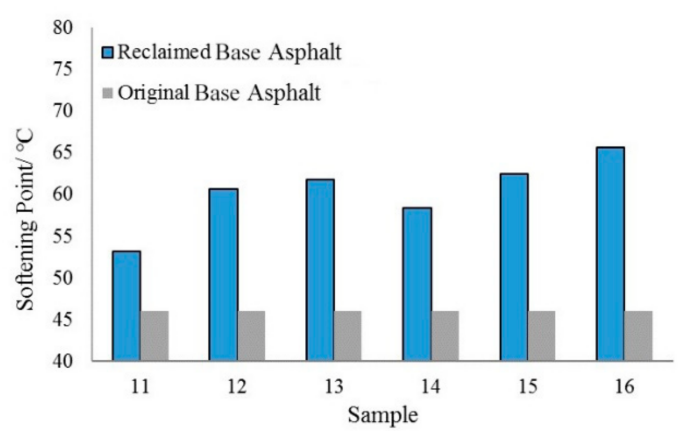

(b)

Figure 6. Softening point test results. (a) Reclaimed SBS (styrene-butadiene-styrene block copolymers) modified asphalt; (b) Reclaimed base asphalt. 


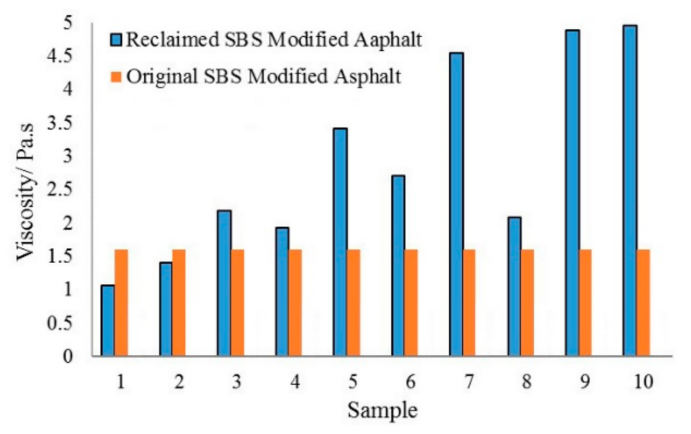

(a)

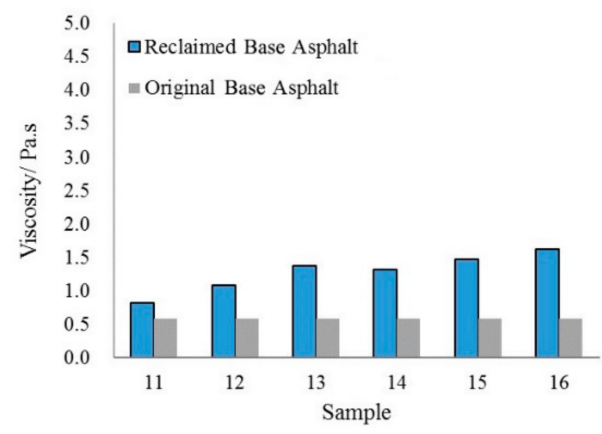

(b)

Figure 7. The $135^{\circ} \mathrm{C}$ viscosity test results. (a) Reclaimed SBS modified asphalt; (b) Reclaimed base asphalt.

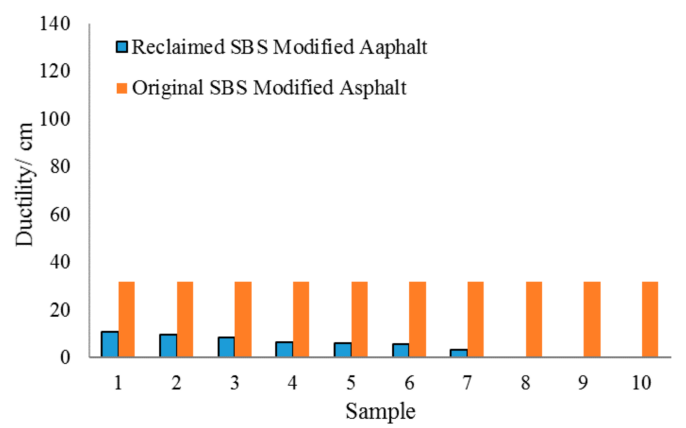

(a)

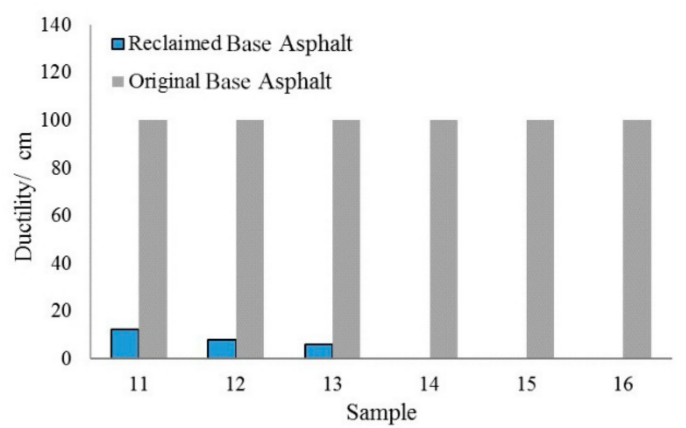

(b)

Figure 8. Ductility test results. (a) Reclaimed SBS modified asphalt; (b) Reclaimed base asphalt. 


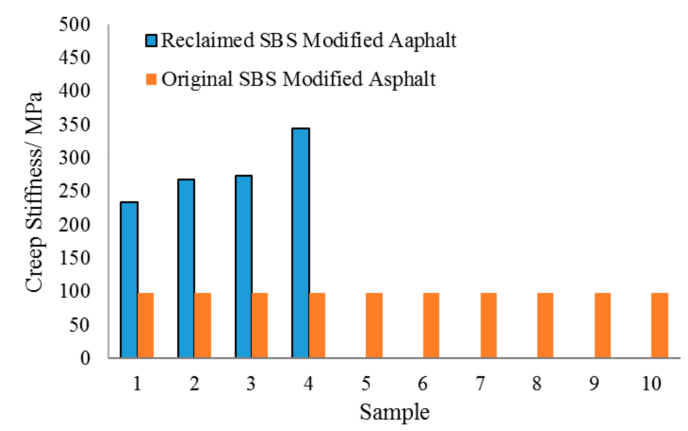

(a)

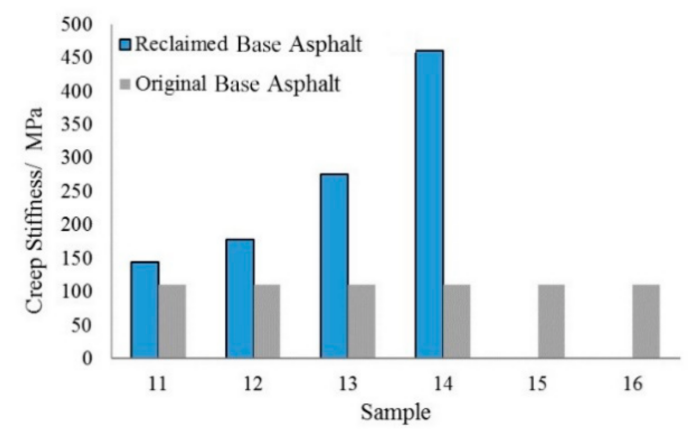

(b)

Figure 9. Creep stiffness test results. (a) Reclaimed SBS modified asphalt; (b) Reclaimed base asphalt.

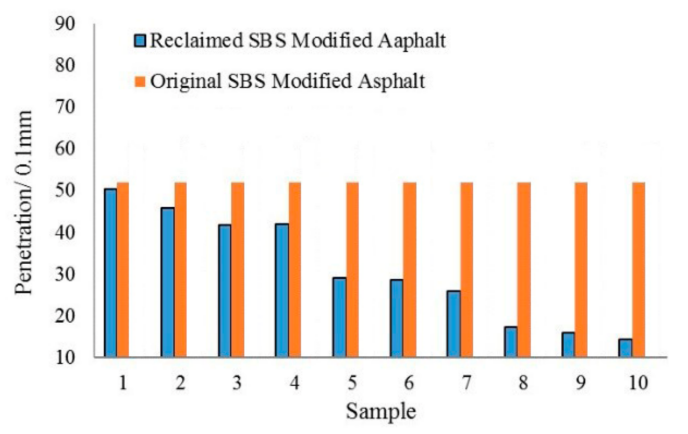

(a)

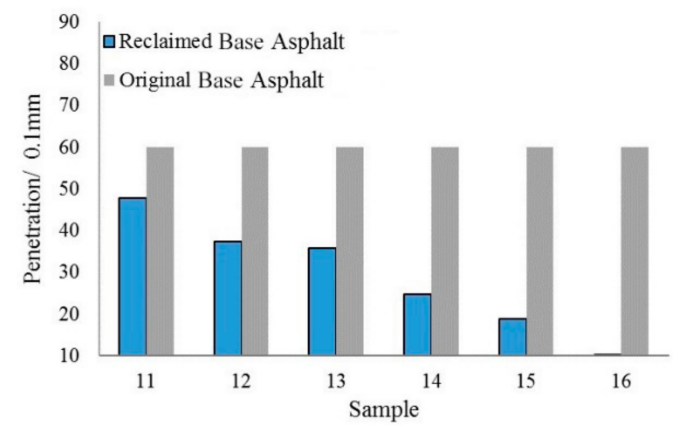

(b)

Figure 10. Penetration test results. (a) Reclaimed SBS modified asphalt; (b) Reclaimed base asphalt. 


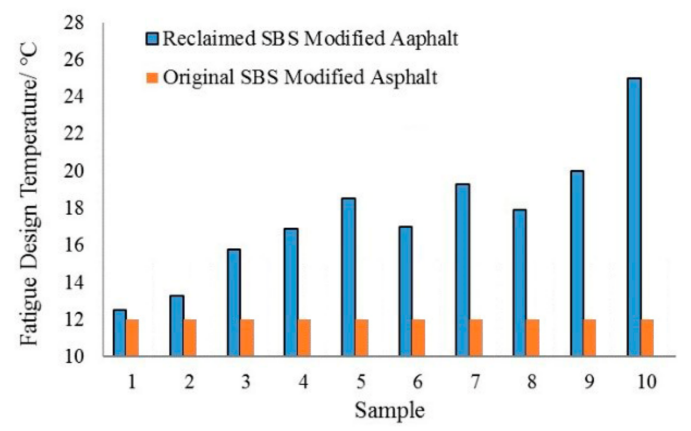

(a)

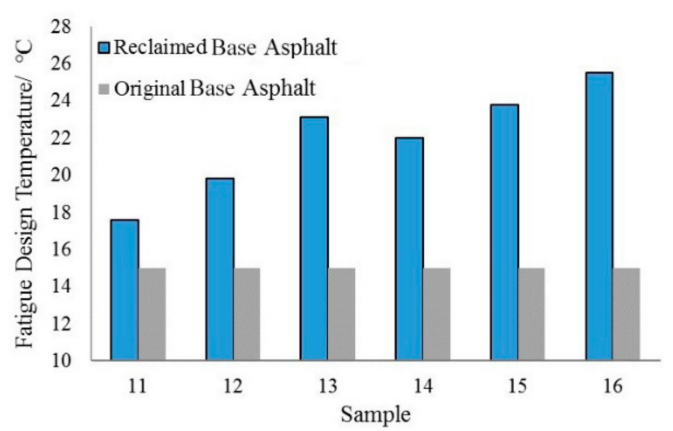

(b)

Figure 11. Fatigue design temperature test results. (a) Reclaimed SBS modified asphalt; (b) Reclaimed base asphalt.

\subsection{High Temperature Performance: Softening Point and Viscosity}

In general, softening point and viscosity have positive correlation to service years, as found in previous studies of RAP binder [1]. This indicates that service years influence high temperature performance much more than milling depth and some other factors. It was assumed that the RABs were subject to similar temperature histories because they had the same source material and were collected from similar climactic conditions in Southern China.

Due to differences in traffic volume, surface layer and mixture gradation, the increase in softening point and viscosity for sample 8 was lower than the other samples as shown in Figures 6 and 7 . The aging process makes asphalt binders become harder, but sample 8 only consisted of middle and lower surface layers, giving it less exposure to the aging experienced by the upper layers. However, softening point and viscosity of samples 1 and 2 became lower than original SBS modified asphalt due to the presence of base asphalt in one of the component layers.

A comparison between sample 1 and 2 shows that the latter has slightly high softening point and viscosity because it covers an upper surface layer, more prone to aging than middle and lower surface layers. The service year and the thickness of the upper layer of sample 3, 5 and 7 are the same, so the longer service time of the middle layer results in a more serious aging degree. Sample 11 and 12 have the same service years and thickness but were located in different layers, showing again that upper layers are more subject to aging. The effect of service year on aging degree can also be seen in samples 12 to 16 .

\subsection{Low Temperature Performance: Ductility and Creep Stiffness}

The ductility of the ten reclaimed SBS modified asphalts was tested at $5{ }^{\circ} \mathrm{C}$ while the ductility of the six reclaimed base asphalts was conducted at $15^{\circ} \mathrm{C}$ due to their decreased performance in ductility compared to SBS binders. 
From Figure 8, it is evident that the ductility of RAB decrease sharply compared with the original binder with the extension of service years, as observed elsewhere [42]. The SBS additive improves the ductility of the binder compared to virgin asphalt considerably [43,44]. The deterioration of the SBS molecular structure by long term aging [45] makes the deterioration of reclaimed SBS modified asphalt more significant than base asphalt, which could be also reflected by the sharp of creep stiffness for the SBS samples.

Unfortunately, ductility and creep stiffness are unavailable for a part of the samples, due to some of the samples being too brittle to be tested. It is for this reason that these two indexes are not suitable for categorizing the aging grades of more brittle RABs.

\subsection{Average Temperature Performance: Penetration and Fatigue Design Temperature}

With the extension of sample service years, the penetration of the RABs declined while the fatigue design temperature increased. The increase of penetration indicates that aging makes asphalt binders stiffer. Fatigue design temperature stands for the critical temperature below which the fatigue factor is more than the required value $(5000 \mathrm{kPa})$. A higher fatigue design temperature represents a weaker fatigue cracking resistance.

Generally, the changing trend of the average temperature performance of RABs caused by aging is as similar as that of high temperature performance. Due to the longer service life of the middle layer, the performance decline of sample 5 and 7 are steeper than that of sample 2 to 4 . Both sample 8 and sample 9 consist of middle and lower layers but sample 9 had a longer life, which made it stiffer and reduced the fatigue cracking resistance.

\section{Discussion}

\subsection{Aging Grade of RABs}

In the recycling of RAP, it is critical to have a way of classifying the RAB, in order to select appropriate uses, mixture production methods and $\mathrm{RAB}$ rejuvenation methods. One important principle of selecting the indexes used to divide aging grades is that they must distinguish different aging grades for different categories of binder. In order to determine the optimal index, $D$ was defined in Equation (1), where $P_{\mathrm{RABs}}$ is the performance for the RABs, while $P_{\text {original }}$ represents the performance of the original asphalt binder.

$$
D=\left(P_{\text {RABs }}-P_{\text {original }}\right) / P_{\text {original }}
$$

The degree of aging is shown in Figure 12. The degree value for softening point and fatigue design temperature were between 0 and 1 . Comparatively, viscosity and penetration had higher degrees of aging and would be more suitable for categorizing aging grades, as they are more sensitive to aging.

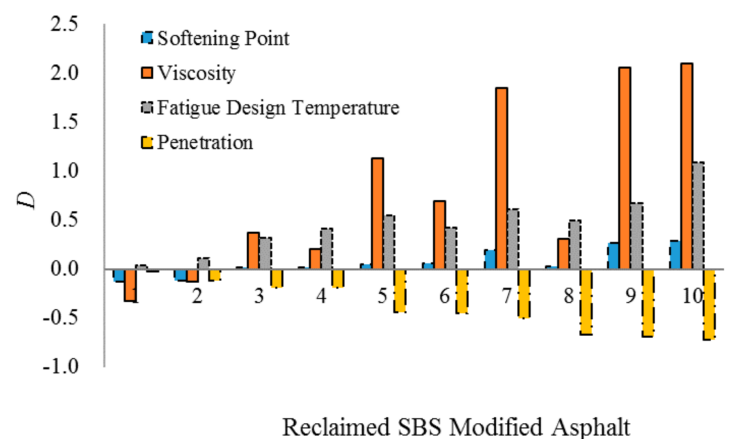

(a)

Figure 12. Cont. 


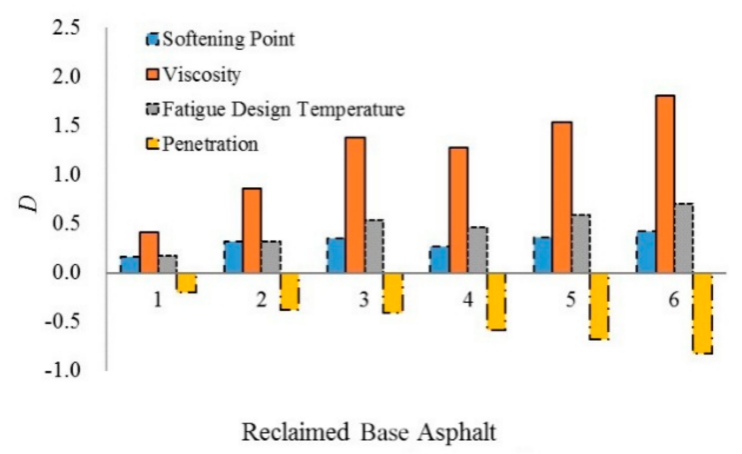

(b)

Figure 12. Degree of aging for RABs. (a) Reclaimed SBS modified asphalt; (b) Reclaimed Base asphalt.

The viscosity of original SBS modified asphalt at $135^{\circ} \mathrm{C}$ was $1.6 \mathrm{~Pa} \cdot \mathrm{s}$. The maximum is $3 \mathrm{~Pa} \cdot \mathrm{s}$ according to the China Technical Specification for Construction of Highway Asphalt Pavement [46]. Based on this, the RABs were divided into six grades as shown in Table 3.

Table 3. Physical properties of original asphalt binders.

\begin{tabular}{|c|c|c|c|c|c|c|c|c|}
\hline \multirow{3}{*}{$\begin{array}{c}\text { Classification Tests }^{1} \\
\mathbf{1 3 5}{ }^{\circ} \mathrm{C} \text { Viscosity } / \mathrm{Pa} \cdot \mathbf{s} \\
\text { Penetration } / 0.1 \mathrm{~mm}\end{array}$} & \multirow{2}{*}{\multicolumn{2}{|c|}{$\begin{array}{c}\text { Reclaimed Base Asphalt } \\
\eta^{2} \leq 1.6\end{array}$}} & \multicolumn{6}{|c|}{ Reclaimed SBS Modified Asphalt } \\
\hline & & & $\eta \leq 1.6$ & & $1.6<\eta \leq 3$ & & $\eta$ & \\
\hline & $P^{3}>30$ & $10<P \leq 30$ & $P>30$ & $P>30$ & $20<P \leq 30$ & $10<P \leq 20$ & $20<P \leq 30$ & $10<P \leq 20$ \\
\hline Sample Number & $11,12,13$ & $14,15,16$ & 1,2 & 3,4 & 6 & 8 & $5, \overline{7}$ & 9,10 \\
\hline Aging Grades & I & II & I & II & III & IV & $\mathrm{V}$ & $\mathrm{V}$ \\
\hline
\end{tabular}

There are many factors influencing the aging grades of RABs, such as climatic conditions, surface layers (upper, middle or lower), traffic volume, service years, and so on. Thus, a decision making tool, AHP which incorporates both qualitative and quantitative factors of complicated systems was introduced. The AHP has increased in use and popularity by simplifying complex decisions to a series of one-on-one comparisons.

It is evident from the analysis above that the depth and service years of the surface layer are the main influence factors because the former represents the aging conditions of the RABs while the latter has high relevance to traffic volume [47]. The analysis mentioned above also showed that aging grades have a positive correlation with service years and surface layer depth, so these two parameters were selected to determine the comprehensive evaluation index (comprehensive service life) of the aging system.

\subsection{Comprehensive Service Life Based on Analytic Hierarchy Process}

\subsubsection{Analytic Hierarchy Process}

Taking an AHP as an example, the structure of the decision hierarchy would as shown in Figure 13. Level 1 is the goal of the system. Level 2 is multi criteria that consist of different factors and this level may include several other levels of sub criteria. The last level (Level 3) is the alternative options. In level 2 there is one comparison matrix corresponding to pair-wise comparisons between all factors with respect to the goal. Specific procedures will be shown from Section 4.2.2 to Section 4.2.5 by using it to calculate the comprehensive service life of RABs. 


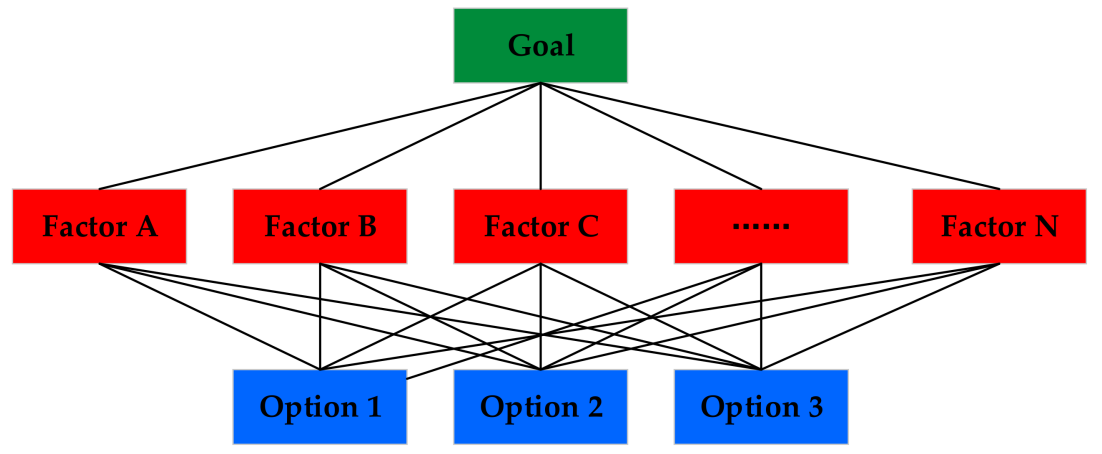

Level 1

Level 2

Figure 13. The structure of two-level analytic hierarchy process (AHP).

\subsubsection{Hierarchical Structure for RABs}

To simplify the evaluation of aging grades of reclaimed asphalt binders, the concept comprehensive service life was put forward to represent the comprehensive aging degree and calculated by using the AHP method.

The first step of AHP was to divide the various factors into an orderly hierarchical structure according to their interaction and affiliation. Then, a judgment matrix is established by connecting analysts' judgments with performance results. Finally, the composition weight of each layer to the system goal is obtained by calculating the maximum eigenvalue and the eigenvector of the judgment matrix.

As shown in Figure 14, the comprehensive service life is affected by the surface layers and their respective service years.

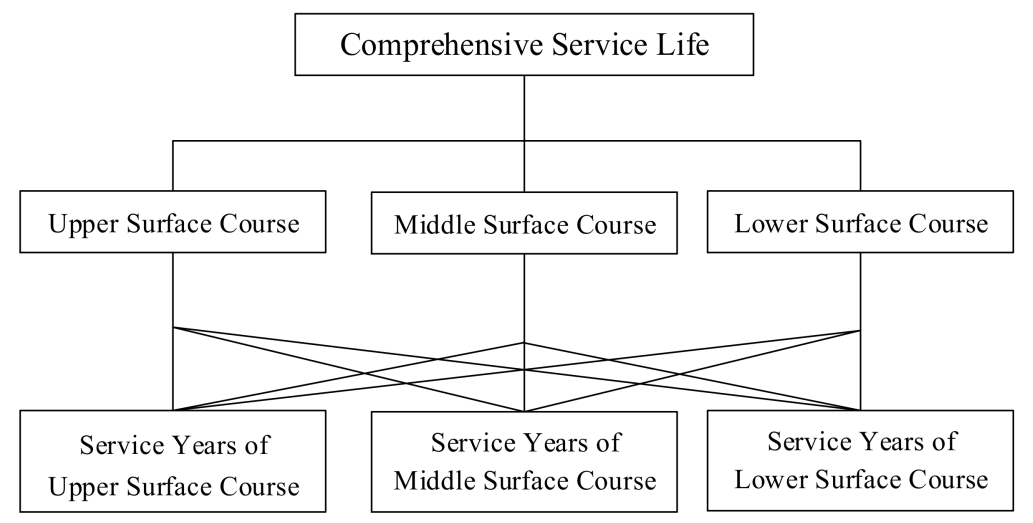

Figure 14. Hierarchical model for determining the comprehensive service life of RABs.

\subsubsection{Calculating the Weight of Each Surface Layer}

To quantify the significance or contribution of different factors to the aging of RABs, numeric scales were determined initially by repeated trial calculations, analysis of performance testing data and engineering experience. The significance of the numeric scales is listed in Table 4. 
Table 4. Significance of the Numeric Scales.

\begin{tabular}{cc}
\hline Numeric Scale & Significance \\
\hline 2.0 & Extremely important \\
1.5 & Clearly important \\
1.0 & Important \\
$(1.0,1.5),(1.5,2.0)$ & Interval of importance \\
Reciprocal & If $b_{i j}$ is the importance ratio of factor $i$ and factor $j, 1 / b_{i j}$ \\
& will be the importance ratio of factor $j$ and factor $i$ \\
\hline
\end{tabular}

The scale of upper surface layer to middle surface layer was 1.5, which means that when subject to the same service year, climatic condition, traffic volume, the aging of upper surface layer was more serious than middle surface layer. Similarly, the scales of the upper surface layer to lower surface layer and middle surface layer to lower surface layer were 1.7 and 1.1, respectively. By the numeric scales, the judgment matrix was given. As shown in Table 5, the composition weight of each layer to the system goal is obtained by calculating the maximum eigenvalue and the eigenvector of the judgment matrix. Thus, the contribution ratio of different layers to the aging of an example consisting of all three layers would be 45:28:27 from upper to lower layers.

Table 5. Judgment Matrix and Weights.

\begin{tabular}{ccccc}
\hline RABs & Upper Surface Layer & Middle Surface Layer & Lower Surface Layer & Weights \\
\hline Upper Surface Layer & 1.0 & 1.5 & 1.7 & 0.45 \\
Middle Surface Layer & 0.7 & 1.0 & 1.1 & 0.28 \\
Lower Surface Layer & 0.6 & 0.9 & 1.0 & 0.27 \\
\hline
\end{tabular}

\subsubsection{Artificial Amendment Coefficient}

Even when milled from the same pavement section, the material compositions of RAP are different with various milling types, including single layer milling, double layer milling and full depth milling. Here, a coefficient was used to quantify the effect of the layer combination on comprehensive service life. The worst situation was that samples only contained the upper layers, allocated with value 1.5 while the best was that samples only contained the lower layers, with value 0.7. The artificial amendment coefficients of other situations ranges in the interval $[0.7,1.5]$. They are presented in Table 6.

Table 6. Layer combination coefficients.

\begin{tabular}{ccccccc}
\hline Combination & Upper + Middle + Lower & Upper + Middle & Middle + Lower & Upper & Middle & Lower \\
\hline Coefficient & 1.1 & 1.3 & 0.8 & 1.5 & 1.2 & 0.7 \\
\hline
\end{tabular}

\subsubsection{Calculating the Comprehensive Service Life of RABs}

The comprehensive service life was calculated by Equation (2) and is listed in Table 7 for each sample. This is a very common equation in AHP. It combines the specific contributions of different factors (here, they are the service years and material composition) with engineering experience (the weights and artificial amendment coefficients) to determine the goal (comprehensive service life) of the system (aging). However, this a repeated trial calculation process just like a study system where the goal will tend to what we expect it to be by repeated adjustment of the weights and artificial amendment coefficients.

$$
P=\left(w_{1} \times P_{1} \times Q_{1}+w_{2} \times P_{2} \times Q_{2}+w_{3} \times P_{3} \times Q_{3}\right) \times \mathrm{n}
$$


In Equation (2), $P$ is the comprehensive service life. $w_{1}, w_{2}, w_{3}$ are the weights of the upper, middle and lower surface layers, respectively. $P_{1}, P_{2}, P_{3}$ are the service years of the upper, middle and lower surface layers, respectively. $Q_{1}, Q_{2}, Q_{3}$ are the material coefficients (If $100 \%$ Reclaimed SBS modified asphalt, $Q=1$; If Reclaimed base asphalt included, $Q=0.65$ ) and $\mathrm{n}$ is the layer combination coefficient.

The data in Table 7 indicated that consistency exists between aging grades and comprehensive service life. That is to say, it would be useful to assess the aging grades of RABs directly by calculating their comprehensive service life.

Anyway, results in Table 7 is based on the field data of reclaimed asphalt pavement collected in this study from the same climatic zone in southern China. Thus, the service years and structural layer levels can be the key influencing factors on the aging grade. This made the comprehensive service life considering structural layer levels possible and feasible. For complicated situations, more factors should be taken into account to determine the comprehensive service life using the AHP.

Table 7. Layer combination coefficients.

\begin{tabular}{|c|c|c|c|c|c|c|c|c|c|c|c|c|c|c|c|c|}
\hline \multirow{3}{*}{$\begin{array}{c}\text { Binder Type Items } \\
\text { Aging Grades } \\
\text { RAB Sample }\end{array}$} & \multicolumn{6}{|c|}{ Reclaimed Base Asphalt } & \multicolumn{10}{|c|}{ Reclaimed SBS Modified Asphalt } \\
\hline & \multicolumn{3}{|c|}{ I } & \multicolumn{3}{|c|}{ II } & \multicolumn{2}{|c|}{ I } & \multicolumn{2}{|c|}{ II } & \multirow{2}{*}{$\begin{array}{c}\text { III } \\
6\end{array}$} & \multirow{2}{*}{$\begin{array}{c}\text { IV } \\
8\end{array}$} & \multicolumn{2}{|c|}{$\mathrm{V}$} & \multicolumn{2}{|c|}{ VI } \\
\hline & 11 & 12 & 13 & 14 & 15 & 16 & 1 & 2 & 3 & 4 & & & 5 & 7 & 9 & 10 \\
\hline $\begin{array}{l}\text { Comprehensive } \\
\text { Service Life }\end{array}$ & 0.37 & 2.03 & 2.70 & 4.73 & 6.08 & 6.75 & 1.09 & 2.27 & 2.26 & 2.85 & 3.03 & 2.92 & 3.35 & 4.08 & 4.37 & 4.03 \\
\hline
\end{tabular}

Based on the results in terms of binder classification and aging grades in this paper, methods to determine the contents of rejuvenation agents and new asphalt in the design of RAP mixtures need further study, which is also the next topic of research of the current project.

\section{Conclusions}

Through investigation and analysis on factors such as surface layers, types of asphalt, service years and milling depth, this study aimed to establish a method to evaluate the aging grades of RABs in order to their recycling. For this purpose, performance tests at high, average and low temperatures were conducted on the various reclaimed asphalt binders collected from sixteen different sites. The penetration and viscosity were found to be more consistent in distinguishing aged binders for both base asphalt and polymer modified asphalt. By these two indexes, the reclaimed base asphalts were classified into two aging grades and reclaimed SBS modified asphalt into six aging grades. Contractors or agents can rejuvenate the old asphalt binders recycled from RAPs according to their aging grades. Another convenient way to determine the aging grades is to find a comprehensive evaluation index which can take the binder type, milling depth, surface layers and service years into account. All these factors have a strong influence on the aging degree of RABs. Finally, the concept, comprehensive service life is found to be a feasible index to classify RAB aging grades that may help save testing time. However, its calculation should incorporate more engineering properties in the future.

Acknowledgments: The authors would like to acknowledge the financial support of the Natural Science Foundation Committee of China (51578481 and 51578480), the China Scholarship Council (201608320211) and the Research and Innovation Plans for Graduates (kyzz15_0363). We would also like to thank the technical support from the Testing Center of Yangzhou University and the Centre for Pavement and Transportation Technology at the University of Waterloo in Canada.

Author Contributions: Peng Xiao and Aihong Kang conceived and designed the experiments; Changjiang Kou performed the experiments; Changjiang Kou and Peter Mikhailenko analyzed the data; Hassan Baaj and Zhengguang Wu contributed guidance and support for the experiments; Changjiang Kou wrote the paper.

Conflicts of Interest: The authors declare no conflict of interest. The sponsors had no role in the design of the study; in the collection, analyses, or interpretation of data; in the writing of the manuscript, and in the decision to publish the results. 


\section{References}

1. Al-Qadi, I.L.; Elseifi, M.A.; Carpenter, S.H. Reclaimed Asphalt Pavement-A Literature Review; Report No.: FHWAICT-07-001; Illinois Center for Transportation: Urbana, IL, USA, 2007.

2. Moghaddam, T.B.; Baaj, H. The use of rejuvenating agents in production of recycled hot mix asphalt: A systematic review. Constr. Build. Mater. 2016, 114, 805-816. [CrossRef]

3. Kennedy, T.W.; Tam, W.; Solaimanian, M. Effect of Reclaimed Asphalt Pavement on Binder Properties Using the Superpave System; Research Report 1250-1; Center for Transportation Research, University of Texas: Austin, TX, USA, 1998.

4. Valdésa, G.; Pérez-Jiméneza, F.; Miróa, R.; Martíneza, A.; Botellaa, R. Experimental study of recycled asphalt mixtures with high percentages of reclaimed asphalt pavement (RAP). Constr. Build. Mater. 2011, 25, 1289-1297. [CrossRef]

5. Vidala, R.; Molinera, E.; Martínez, G.; Rubio, M.C. Life cycle assessment of hot mix asphalt and zeolite-based warm mix asphalt with reclaimed asphalt pavement. Resour. Conserv. Recycl. 2013, 74, 101-114. [CrossRef]

6. Noferini, L.; Simone, A.; Sangiorgi, C.; Mazzotta, F. Investigation on performances of asphalt mixtures made with Reclaimed Asphalt Pavement: Effects of interaction between virgin and RAP bitumen. Int. J. Pavement Res. Technol. 2017, 10, 322-332. [CrossRef]

7. Mallick, R.B.; Kandhal, P.S.; Bradbury, R.L. Using warm-mix asphalt technology to incorporate high percentage of reclaimed asphalt pavement material in asphalt mixtures. Transp. Res. Rec. 2008, 2051, 71-79. [CrossRef]

8. Bowersa, B.F.; Mooreb, J.; Huangb, B. Blending efficiency of reclaimed asphalt pavement: An approach utilizing rheological properties and molecular weight distributions. Fuel 2014, 135, 63-68. [CrossRef]

9. Zaumanis, M.; Mallick, R.B.; Poulikakos, L.; Frank, R. Influence of six rejuvenators on the performance properties of reclaimed asphalt pavement (RAP) binder and 100\% recycled asphalt mixtures. Constr. Build. Mater. 2014, 71, 538-550. [CrossRef]

10. McDaniel, R.S.; Shah, A.; Huber, G.A. Effects of reclaimed asphalt pavement content and virgin binder grade on properties of plant produced mixes. Road Mater. Pavement 2012, 13, 161-182. [CrossRef]

11. Baaj, H.; Ech, M.; Tapsoba, N.; Sauzeat, C.; di Benedetto, H. Thermo-mechanical characterization of asphalt mixtures modified with high contents of asphalt shingle modifier (ASM) and reclaimed asphalt pavement (RAP). Mater. Struct. 2013, 46, 1747-1763. [CrossRef]

12. Tapsoba, N.; Sauzéat, C.; di Benedetto, H. Behaviour of asphalt mixtures containing reclaimed asphalt pavement and asphalt shingle. Road Mater. Pavement 2014, 15, 330-347. [CrossRef]

13. Ongel, A.; Hugener, M. Aging of bituminous mixes for rap simulation. Constr. Build. Mater. 2014, 68, 49-54. [CrossRef]

14. Mallick, R.B.; El-Korchi, T. Pavement Engineering Principles and Practice, 2nd ed.; CRC Press: Boca Raton, FL, USA, 2009; pp. 18-20; ISBN 978-1439870358.

15. Siddiqui, M.N.; Ali, M.F. Studies on the aging behaviour of the Arabian asphalts. Fuel 1999, 78, $1005-1015$. [CrossRef]

16. Le Guern, M.; Chailleux, E.; Farcas, F.; Dreessen, S.; Mabille, I. Physico-chemical analysis of five hard bitumens: Identification of chemical species and molecular organization before and after artificial aging. Fuel 2010, 89, 3330-3339. [CrossRef]

17. Lu, J. Aging Behaviour and Recycling Technique of Asphalt Pavement. Ph.D. Thesis, Chang'an University, Xi'an, China, 2008.

18. Liu, L. Recycled asphalt extracted from asphalt pavement. Highw. Eng. 2011, 36, 38-43.

19. Ji, J.; Luo, X.; Yan, B.; Xu, S. Determination of critical aging time and optimum content of recycling agent. Highway 2006, 1, 146-170.

20. Kuang, D.; Yu, J. Effect of Rejuvenator on Properties of Aged Bitumen of Different Aging Degree. Highway 2011, 5, 153-158.

21. Dondi, G.; Mazzotta, F.; Simone, A.; Vignali, V.; Sangiorgi, C.; Lantieri, C. Evaluation of different short term aging procedures with neat, warm and modified binders. Constr. Build. Mater. 2016, 106, 282-289. [CrossRef]

22. Bonemazzi, F.; Braga, V.; Corrieri, R.; Giavarini, C.; Sartori, F. Characteristics of polymers and polymer-modified binders. Transp. Res. Rec. 1996, 1535, 36-47. [CrossRef]

23. Yildirim, Y. Polymer modified asphalt binders. Constr. Build. Mater. 2007, 21, 66-72. [CrossRef]

24. Chen, J.; Liao, M.; Shiah, M. Asphalt modified by styrene-butadiene-styrene triblock copolymer: Morphology and model. J. Mater. Civ. Eng. 2002, 14, 224-229. [CrossRef] 
25. Saaty, T.L. The Analytic Hierarchy Process: Planning, Priority Setting, Resource Allocation; McGraw-Hill: New York, NY, USA, 1980.

26. Saaty, R.W. The analytic hierarchy process-What it is and how it is used. Math. Model. 1987, 9, 161-176. [CrossRef]

27. Vaidya, O.S.; Kumar, S. Analytic hierarchy process: An overview of applications. Eur. J. Oper. Res. 2004, 169, 1-29. [CrossRef]

28. Smith, J.T.; Tighe, S.L. The Analytical Hierarchy Process as a Tool for Infrastructure Management. Transp. Res. Rec. 2006, 1940, 13-20. [CrossRef]

29. Guo, D.J.; Zhou, W.H.; Sha, A.M.; Bai, R.Y. Application of Uncertainty Analytic Hierarchy Process Method for Asphalt Pavement Construction Quality Control in China. Transp. Res. Rec. 2009, 2098, 43-50. [CrossRef]

30. Zhang, Y.; Li, L.H. Asphalt Pavement Construction Quality Evaluation Model and Weight Calculation Based on Analytic Hierarchy Process. J. Tongji Univ. 2011, 39, 253-258. [CrossRef]

31. Xiao, Y.C.; Zhang, J.P.; Li, J.; Chang, M.F. Reliability index study of asphalt concrete pavement construction based on analytical hierarchy process. Highway 2013, 7, 1-4. [CrossRef]

32. Liu, M.L.; Shi, Z.W.; Wang, L.M. Comprehensive performance evaluation of warm mix asphalt based on the analytical hierarchy process and fuzzy evaluation theory. J. China Foreign Highw. 2015, 35, $246-250$. [CrossRef]

33. Li, H.Y.; Li, F.Z.; Fan, H.H.; He, Y.B. Evaluation for damaged condition of asphalt pavement based on fuzzy-AHP method. Highw. Eng. 2012, 6, 40-44. [CrossRef]

34. McDaniel, R.S.; Anderson, R.M. Recommended Use of Reclaimed Asphalt Pavement in Superpave Mix Design Method; National Cooperative Highway Research Program (Project D 9-12); Contractor's Final Report; National Academy Press: Washington, DC, USA, 2000.

35. Mikhailenko, P.; Baaj, H. Overview of Current Asphalt Binder Extraction and Recovery Practices. In Proceedings of the 2017 Transportation Association of Canada Conference, St. John's, NL, Canada, 24-27 September 2017.

36. Ma, T.; Zhang, D.L.; Huang, X.M. Influential factors and improvement of extraction and recovery of SBS modified asphalt. J. Southeast Univ. 2008, 38, 40-42.

37. Standard Test Method for Quantitative Extraction of Bitumen from Bituminous Paving Mixture; ASTM D2172; ASTM International: West Conshohocken, PA, USA, 2017.

38. Test Specification of Asphalt and Asphalt Mixtures for Highway of China; JTG E20-2011; China Communications Press Co., Ltd.: Beijing, China, 2011.

39. Standard Test Method for Viscosity Determination of Asphalt at Elevated Temperatures Using a Rotational Viscometer; ASTM D4402/D4402M-12; ASTM International: West Conshohocken, PA, USA, 2002.

40. Standard Test Method for Determining the Rheological Properties of Asphalt Binder Using a Dynamic Shear Rheometer; ASTM D7175-08; ASTM International: West Conshohocken, PA, USA, 2005.

41. Determining the Flexural Creep Stiffness of Asphalt Binder Using the Bending Beam Rheometer (BBR); ASTM D6648-08; ASTM International: West Conshohocken, PA, USA, 2016.

42. Fernández-Gómez, W.D.; Quintana, H.R.; Lizcano, F.R. A review of asphalt and asphalt mixture aging. Ing. Investig. 2013, 33, 5-12.

43. Cortizo, M.S.; Larsen, D.O.; Bianchetto, H.; Alessandrini, J.L. Effect of the thermal degradation of SBS copolymers during ageing of modified asphalts. Polym. Degrad. Stabil. 2004, 86, 275-282. [CrossRef]

44. Kou, C.; Kang, A.; Zhang, W. Methods to prepare polymer modified bitumen samples for morphological observation. Constr. Build. Mater. 2015, 81, 93-100. [CrossRef]

45. Daranga, C. Characterization of Aged Polymer Modified Asphalt Cements for Recycling Purposes. Ph.D. Thesis, Louisiana State University, Shreveport, LA, USA, 2005.

46. Technical Specification for Construction of Highway Asphalt Pavement; JTG F40-2004; China Communications Press Co., Ltd.: Beijing, China, 2004.

47. Lu, X.; Sandman, B.; Redelius, P. Aging Characteristics of Polymer Modified Binders in Porous Asphalt Pavements. In Proceedings of the 11th International Conference of Asphalt Pavement, Nagoya, Japan, 1-6 August 2010.

(C) 2017 by the authors. Licensee MDPI, Basel, Switzerland. This article is an open access article distributed under the terms and conditions of the Creative Commons Attribution (CC BY) license (http:/ / creativecommons.org/licenses/by/4.0/). 